\title{
Anticancer therapy within the last 30 days of life: results of an audit and re-audit cycle from an Australian regional cancer centre
}

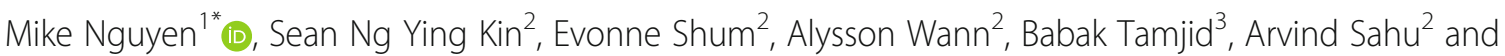
Javier Torres ${ }^{2}$

\begin{abstract}
Background: The therapeutic landscape in medical oncology continues to expand significantly. Newer therapies, especially immunotherapy, offer the hope of profound and durable responses with more tolerable side effect profiles. Integrating this information into the decision making process is challenging for patients and oncologists. Systemic anticancer treatment within the last thirty days of life is a key quality of care indicator and is one parameter used in the assessment of aggressiveness of care.
\end{abstract}

Methods: A retrospective review of medical records of all patients previously treated at Goulburn Valley Health oncology department who died between 1 January 2015 and 30 June 2018 was conducted. Information collected related to patient demographics, diagnosis, treatment, and hospital care within the last 30 days of life. These results were presented to the cancer services meeting and a quality improvement intervention program was instituted. A second retrospective review of medical records of all patients who died between 1 July 2018 and 31 December 2018 was conducted in order to measure the effect of this intervention.

Results: The initial audit period comprised 440 patients. 120 patients (27\%) received treatment within the last 30 days of life. The re-audit period comprised 75 patients. 19 patients (25\%) received treatment within the last 30 days of life. Treatment rates of chemotherapy reduced after the intervention in contrast to treatment rates of immunotherapy which increased. A separate analysis calculated the rate of mortality within 30 days of chemotherapy from the total number of patients who received chemotherapy was initially $8 \%$ and $2 \%$ in the reaudit period. Treatment within the last 30 days of life was associated with higher use of aggressive care such as emergency department presentation, hospitalisation, ICU admission and late hospice referral. Palliative care referral rates improved after the intervention.

Conclusion: This audit demonstrated that a quality improvement intervention can impact quality of care indicators with reductions in the use of chemotherapy within the last 30 days of life. However, immunotherapy use increased which may be explained by increased access and a better risk benefit balance.

Keywords: Quality of care, Aggressiveness, Immunotherapy, Chemotherapy, Mortality, Palliative care, Audit, Service improvement

\footnotetext{
* Correspondence: mikemcnguyen@gmail.com

${ }^{1}$ Austin Health, Melbourne, Australia

Full list of author information is available at the end of the article
}

(c) The Author(s). 2020 Open Access This article is distributed under the terms of the Creative Commons Attribution 4.0 International License (http://creativecommons.org/licenses/by/4.0/), which permits unrestricted use, distribution, and reproduction in any medium, provided you give appropriate credit to the original author(s) and the source, provide a link to the Creative Commons license, and indicate if changes were made. The Creative Commons Public Domain Dedication waiver (http://creativecommons.org/publicdomain/zero/1.0/) applies to the data made available in this article, unless otherwise stated. 


\section{Background}

There have been significant recent developments in the treatment of cancer with many new treatments demonstrating clinical evidence for improved survival and quality of life (QOL). Systemic anticancer therapy (SACT) now includes cytotoxic chemotherapy, endocrine or hormonal agents, targeted or biologic agents and immune checkpoint inhibitors. Non-chemotherapy treatments are often associated with simpler routes of administration, less but not negligible adverse effect profiles and the potential of profound and durable clinical responses. This has made the decision making process for commencing, continuing and ceasing SACT more complex and requires a careful consideration of key factors, specifically disease biology, patient and family expectations, and clinician biases.

Earle et al. [1] have proposed several indicators for the assessment of quality of care near the end of life including the rate of chemotherapy administration; emergency department (ED) presentation, hospitalisation and intensive care unit (ICU) admission; and lack of or late referral to palliative care and hospice services. Over the last few decades, there is a trend towards more aggressive care with US registry studies finding an increase in patients receiving chemotherapy within 14 days of death; and increased rates of ED presentation, hospitalisation and ICU admission in the last month of life [2]. Use of chemotherapy is associated with higher rates of cardiopulmonary resuscitation and mechanical ventilation, late hospice referral, death in ICU, and death in a nonpreferred place [3]. In the current context of immune checkpoint inhibitors, use near the end of life is associated with poorer performance status, lower hospice enrolment and higher rates of death in hospital [4].

The rationale for SACT with palliative intent is primarily to improve or maintain quality of life. Despite this objective, the quality of life of patients as assessed by psychological and physical distress in the final week of life has been found to not improve in patients with moderate or poor performance status who received chemotherapy and in fact worsens in patients with good or excellent performance status who received chemotherapy [5].

There is increasing evidence of the benefit of early involvement of palliative care for patients with cancer. The seminal randomised control study by Temel and colleagues [6] demonstrated early palliative care consultation for patients with non small cell lung cancer (NSCLC) improved QOL, mood and depressive symptoms, and survival by more than two months. A secondary analysis of this study demonstrated that palliative care did not affect the number of chemotherapy regimens administered, but that chemotherapy near the end of life was reduced and hospice enrolment was higher [7]. Both the American Society of Clinical Oncology (ASCO) and the European Society of Medical
Oncology (ESMO) have made recommendations in clinical practice guidelines for the concurrent use of SACT and early involvement of palliative care services for patients with advanced cancer $[8,9]$.

The first large scale report of mortality within 30 days of chemotherapy emanated from the National Confidential Enquiry into Patient Outcome and Death (NCEPOD) conducted in the United Kingdom [10]. The reported rate of mortality within 30 days of SACT was $2 \%$ and has become the historical benchmark. Subsequently, several centres have published data related to SACT within the last 30 days of life [4, 11-28]. A selection of studies are summarised in Table 1 with focus on recent publications and the Australasian context. Comparisons between these studies are difficult for several reasons; studies differed with regard to: the included and excluded tumour types, treatment with curative and palliative intent, and treatment modality. Only three reports included immune checkpoint inhibitors. In addition, the studies reported different outcome measures most commonly the number of deaths within 30 days of treatment as a proportion of all patients who received treatment and, less commonly, as the number of deaths within 30 days of treatment as a proportion of all deaths.

Subsequent to NCEPOD, Christie Cancer Centre in the United Kingdom implemented its key recommendation to review all deaths within 30 days of SACT at a morbidity and mortality meeting and reassess progress through an audit process. Over a four year period, this practice did not reduce the rate of deaths within 30 days of SACT and had a minor but statistically insignificant reduction in the rate of treatment related deaths [22]. In contrast, Wilson et al. reported two audits performed at Auckland Hospital six years apart [19]. Mortality within 30 days of treatment with chemotherapy fell minimally with rates of $2.8 \%$ in 2009 and $2.2 \%$ in 2015 . They proposed a series of clinical interventions that have informed this improvement implementation plan.

The aim of the study was to identify the rates of SACT within the last 30 days of life at the institution in order to compare with published benchmarks. We examined the use of the different types of SACT to observe any changing trends in practice given the development of new therapies, especially in the contemporary paradigm of immune checkpoint inhibitors. The audit also assessed other quality of care and aggressiveness of care parameters. Results from the initial audit informed the implementation of a service improvement plan which was then followed by a re-audit to assess any effect this improvement plan had on clinical practice. This study is novel in the emerging era of immune checkpoint inhibitors and contributes to our understanding of quality use 
Table 1 Summary of studies reporting systemic anticancer therapy near the end of life

\begin{tabular}{|c|c|c|c|c|}
\hline Author & Country & Population studied & Treatment included & $\begin{array}{l}\text { Treatment rate within last } \\
30 \text { days of life }\end{array}$ \\
\hline Gilsch 2019 [4] & USA & $\begin{array}{l}\text { Deaths of patients who received } \\
\text { immune checkpoint inhibitors }\end{array}$ & I & $27 \%$ \\
\hline Ang 2018 [11] & New Zealand & Patients who received SACT & CT TI & $5.2 \%$ \\
\hline Burgers 2018 [12] & The Netherlands & $\begin{array}{l}\text { Patients with stage III or IV lung cancer } \\
\text { treated with SACT }\end{array}$ & $\mathrm{CT}$ & $\begin{array}{l}6.2 \% \text { (within } 30 \text { days of first } \\
\text { cycle of chemotherapy) }\end{array}$ \\
\hline Gllbar 2018 [13] & Australia & Patients who received SACT & $\mathrm{CT} \mathrm{T}$ & $5.6 \%$ \\
\hline Hiramoto 2018 [14] & Japan & $\begin{array}{l}\text { Deaths of patients who received SACT } \\
\text { with palliative intent }\end{array}$ & $C T$ & $16.7 \%$ \\
\hline Massa 2018 [15] & Italy & $\begin{array}{l}\text { Patients with metastatic colorectal cancer } \\
\text { who received SACT }\end{array}$ & $\mathrm{CT}$ & 7.1\% (last 14 days of life) \\
\hline Dasch 2017 [16] & Germany & Inpatient deaths of patients with cancer & $\mathrm{CT}$ & $38.3 \%$ \\
\hline Falchook 2017 [17] & USA & $\begin{array}{l}\text { Patients with metastatic lung, colorectal, } \\
\text { breast, pancreas and prostate cancer }\end{array}$ & $C T$ & $\begin{array}{l}10.1-14.1 \% \text { (within the last } \\
14 \text { days of life) }\end{array}$ \\
\hline Kraut 2017 [18] & USA & Deaths of patients with cancer & CT & $6-16 \%$ \\
\hline Wilson 2017 [19] & New Zealand & Patients who received SACT & $\mathrm{CT}$ & $2.2 \%$ \\
\hline \multirow[t]{2}{*}{ Wallington 2016 [20] } & \multirow[t]{2}{*}{ UK } & $\begin{array}{l}\text { Patients with lung cancer who } \\
\text { received SACT }\end{array}$ & СT T & $8 \%$ \\
\hline & & $\begin{array}{l}\text { Patients with breast cancer who } \\
\text { received SACT }\end{array}$ & CTT & $2 \%$ \\
\hline Wein 2016 [21] & Australia & $\begin{array}{l}\text { Deaths of patients managed with } \\
\text { palliative intent }\end{array}$ & CTE T & $26 \%$ \\
\hline Khoja 2015 [22] & UK & Deaths of patients who received SACT & CT TI & $4 \%$ \\
\hline Pacetti 2015 [23] & Italy & $\begin{array}{l}\text { Deaths of patients who received SACT with } \\
\text { palliative intent }\end{array}$ & $\mathrm{CT}$ & $24.3 \%$ \\
\hline Philip 2015 [24] & Australia & Metastatic non small cell lung cancer & $C T$ & 1\% (last 14 days of life) \\
\hline Andelkovic 2013 [25] & Australia & Patients who received SACT & CT T & $6.9 \%$ \\
\hline Zdenkowski 2013 [26] & Australia & $\begin{array}{l}\text { Patients who received SACT with } \\
\text { palliative intent }\end{array}$ & CT T & $12.2 \%$ \\
\hline Yoong 2012 [27] & Australia & Patients who received SACT & $\mathrm{CT} \mathrm{T}$ & $3.4 \%$ \\
\hline Kao 2009 [28] & Australia & $\begin{array}{l}\text { Deaths of patients managed with } \\
\text { palliative intent }\end{array}$ & $C T$ & $10 \%$ \\
\hline Mort 2008 [10] & UK & Patients who received SACT & CT & $2 \%$ \\
\hline
\end{tabular}

Figure Legends: CT - chemotherapy, T - targeted therapy, I - immune checkpoint inhibitor, E - endocrine / hormonal therapy

of SACT, aggressiveness of care near the end of life and institution based interventions to improve the quality of patient care.

\section{Methods}

\section{Data collection}

Data collected included age, gender, tumour type, performance status, intent of treatment, modality of systemic anticancer treatment, number of previous treatment lines, date of last treatment, date of death, date of referral to palliative care or hospice service, number of emergency department presentations, number of hospital admissions and number of intensive care unit admissions within the last 30 days of life. Systemic anticancer treatment was defined as cytotoxic chemotherapy, endocrine or hormonal treatments, targeted or biologic agents and immune checkpoint inhibitors.

\section{Initial data collection}

A retrospective review was conducted of medical records for all patients managed at the Goulburn Valley Health oncology department who died between 1 January 2015 and 30 June 2018.

\section{Improvement implementation plan}

The following improvement implementation plan was enacted.

- Results were presented to the local cancer services educational meeting to an audience comprising medical oncologists, other medical staff, chemotherapy unit nurses, research nurses, specialist cancer support nurses and palliative care 
health professionals. This was conducted within a week of the conclusion of the audit period.

- Palliative care and community hospice services contact details were collated into a single resource and distributed to medical oncologists and other clinicians. This was conducted within a week of the conclusion of the audit period.

- Discussion at weekly departmental meeting of all patients being considered for anticancer therapy with performance status Eastern Cooperative Oncology Group (ECOG) score 3 or greater; or cases of concern for any other reason

- All clinicians to assess and record patient's performance status at commencement of anticancer treatment and at each subsequent outpatient clinic review

- Review of all cases of anticancer treatment within the last 30 days of life at monthly departmental mortality meeting

- Commitment to repeat audit in order to assess improvement

\section{Repeat data collection}

A retrospective review was repeated of medical records for all patients managed at the Goulburn Valley Health oncology department who died between 1 July 2018 and 31 December 2018.

\section{Statistical analysis}

The data was analysed using descriptive statistical techniques.

\section{Results}

Audit

\section{Patient characteristics}

In the initial audit period, there were 440 patients analysed. Patient characteristics are summarised in Table 2. $60 \%$ were male. The average age was 72.5 years. Only $11 \%$ had a haematological diagnosis. Patients with performance status ECOG score 0 or 1 comprised 23\%, ECOG $240 \%$ and ECOG 3 or $438 \%$ of the total. The most common diagnoses were lung (87 patients), colorectal (62 patients), breast (42 patients), prostate (40 patients) and pancreas (34 patients) (Table 6).

\section{Anticancer treatment}

Details of treatments are described in Table 2 and Table 3. 20\% of patients had not received any anticancer therapy and managed solely with best supportive care. $39 \%$ had received one line of treatment, $25 \%$ had received two lines of treatment and $17 \%$ had received three or more lines of treatment. 120 patients of the total 440 deaths $(27 \%)$ had received anticancer treatment within the last 30 days of life.

66 of 243 patients (27\%) whose last anticancer treatment was chemotherapy received chemotherapy within the last 30 days of life. This indicator was higher with the other treatment modalities: $43 \%$ in targeted / biologic agents, $47 \%$ in endocrine / hormonal agents and $47 \%$ in immune checkpoint inhibitors. Of the total number of patients who received chemotherapy, treatment within the last 30 days of life represented $8 \%$ of patients.

Table 2 Characteristics of patients in the the audit period

\begin{tabular}{|c|c|c|c|c|c|c|}
\hline & \multicolumn{2}{|c|}{ All Patients } & \multicolumn{2}{|c|}{ Treatment within last 30 days } & \multicolumn{2}{|c|}{ No treatment within last 30 days } \\
\hline & Number & Percent & Number & Percent & Number & Percent \\
\hline & 440 & & 120 & $27 \%$ & 320 & $73 \%$ \\
\hline \multicolumn{7}{|l|}{ Sex } \\
\hline Male & 263 & $60 \%$ & 67 & $56 \%$ & 196 & $61 \%$ \\
\hline Female & 177 & $40 \%$ & 53 & $44 \%$ & 124 & $39 \%$ \\
\hline \multicolumn{7}{|l|}{ Discipline } \\
\hline Oncology & 392 & $89 \%$ & 103 & $26 \%$ & 289 & $74 \%$ \\
\hline Hematology & 48 & $11 \%$ & 17 & $35 \%$ & 31 & $65 \%$ \\
\hline Average age (years) & 72.5 & & 71 & & 73.3 & \\
\hline \multicolumn{7}{|l|}{ Performance status } \\
\hline ECOG 0 or 1 & 99 & $23 \%$ & 34 & $28 \%$ & 65 & $20 \%$ \\
\hline ECOG 2 & 175 & $40 \%$ & 44 & $37 \%$ & 131 & $41 \%$ \\
\hline ECOG 3 or 4 & 166 & $38 \%$ & 42 & $35 \%$ & 124 & $39 \%$ \\
\hline \multicolumn{7}{|l|}{ Line of treatment } \\
\hline Never treated & 89 & $20 \%$ & & & 89 & $28 \%$ \\
\hline First line & 170 & $39 \%$ & 59 & $49 \%$ & 111 & $35 \%$ \\
\hline Second line & 108 & $25 \%$ & 36 & $30 \%$ & 72 & $23 \%$ \\
\hline Third line or greater & 73 & $17 \%$ & 25 & $21 \%$ & 48 & $15 \%$ \\
\hline
\end{tabular}


Table 3 Treatment and aggressiveness of care in the audit period

\begin{tabular}{|c|c|c|c|c|c|c|}
\hline & \multicolumn{2}{|c|}{ All Patients } & \multicolumn{2}{|c|}{ Treatment within last 30 days } & \multicolumn{2}{|c|}{ No treatment within last 30 day } \\
\hline & Number & Percent & Number & Percent & Number & Percent \\
\hline \multicolumn{7}{|l|}{ Last treatment type } \\
\hline Chemotherapy & 243 & & 66 & $27 \%$ & 177 & $73 \%$ \\
\hline Targeted/biologic & 47 & & 20 & $43 \%$ & 27 & $57 \%$ \\
\hline Endocrine/hormonal & 53 & & 25 & $47 \%$ & 28 & $53 \%$ \\
\hline Immunotherapy & 30 & & 14 & $47 \%$ & 16 & $53 \%$ \\
\hline \multicolumn{7}{|l|}{ Treatment intent } \\
\hline Curative & 19 & $4 \%$ & 5 & $4 \%$ & 14 & $4 \%$ \\
\hline Palliative & 421 & $96 \%$ & 115 & $96 \%$ & 306 & $96 \%$ \\
\hline \multicolumn{7}{|l|}{ Parameters for aggressiveness of care } \\
\hline Palliative care referral & 272 & $65 \%$ & 67 & $58 \%$ & 205 & $67 \%$ \\
\hline Palliative care referral beyond last 30 days & 178 & $42 \%$ & 32 & $28 \%$ & 146 & $48 \%$ \\
\hline More than one emergency presentations & 43 & $10 \%$ & 21 & $18 \%$ & 22 & $7 \%$ \\
\hline More than one hospitalisation & 49 & $12 \%$ & 20 & $17 \%$ & 29 & $9 \%$ \\
\hline Hospitalisation 14 or more days & 60 & $14 \%$ & 13 & $11 \%$ & 47 & $15 \%$ \\
\hline ICU admission & 16 & $4 \%$ & 7 & $6 \%$ & 9 & $3 \%$ \\
\hline
\end{tabular}

\section{Aggressiveness of care}

421 (96\%) were treated with palliative intent. Of these, $65 \%$ of patients had a referral to palliative care or community hospice services. Referral was often late with $58 \%$ of referrals made within the last 30 days of life. Receiving treatment within the last 30 days of life when compared with not, was associated with higher rates of late palliative care referral (72\% compared with 52\%), more than one ED presentation (18\% vs $7 \%)$, more than one hospital admission (17\% vs 9\%) and ICU admission (6\% vs $3 \%)$.

\section{Re-audit}

\section{Patient characteristics}

The re-audit period comprised 75 patients as summarised in Table $4.53 \%$ were male. The average age was

Table 4 Characteristics of patients in the the re-audit period

\begin{tabular}{|c|c|c|c|c|c|c|}
\hline & \multicolumn{2}{|c|}{ All Patients } & \multicolumn{2}{|c|}{ Treatment within last 30 days } & \multicolumn{2}{|c|}{ No treatment within last 30 days } \\
\hline & Number & Percent & Number & Percent & Number & Percent \\
\hline & 75 & & 19 & $25 \%$ & 56 & $75 \%$ \\
\hline \multicolumn{7}{|l|}{ Sex } \\
\hline Male & 40 & $53 \%$ & 10 & $53 \%$ & 30 & $54 \%$ \\
\hline Female & 35 & $47 \%$ & 9 & $47 \%$ & 26 & $46 \%$ \\
\hline \multicolumn{7}{|l|}{ Discipline } \\
\hline Oncology & 65 & $87 \%$ & 19 & $29 \%$ & 46 & $71 \%$ \\
\hline Hematology & 10 & $13 \%$ & 0 & $0 \%$ & 10 & $100 \%$ \\
\hline Average age (years) & 70.1 & & 66.9 & & 71.1 & \\
\hline \multicolumn{7}{|l|}{ Performance status } \\
\hline ECOG 0 or 1 & 30 & $40 \%$ & 4 & $21 \%$ & 26 & $46 \%$ \\
\hline ECOG 2 & 29 & $39 \%$ & 7 & $37 \%$ & 22 & $39 \%$ \\
\hline ECOG 3 or 4 & 16 & $21 \%$ & 8 & $42 \%$ & 8 & $14 \%$ \\
\hline \multicolumn{7}{|l|}{ Line of treatment } \\
\hline Never treated & 6 & $8 \%$ & & & 6 & $11 \%$ \\
\hline First line & 25 & $33 \%$ & 3 & $16 \%$ & 22 & $39 \%$ \\
\hline Second line & 25 & $33 \%$ & 10 & $53 \%$ & 15 & $27 \%$ \\
\hline Third line or greater & 19 & $25 \%$ & 6 & $32 \%$ & 13 & $23 \%$ \\
\hline
\end{tabular}


70 years. Only $13 \%$ had a haematological diagnosis. Patients with performance status ECOG score 0 or 1 comprised $40 \%$, ECOG $239 \%$ and ECOG 3 or $421 \%$ of the total. The most common diagnoses were colorectal (14 patients), lung (10 patients), prostate (7 patients), breast (6 patients), upper GI (5 patients) and melanoma (5 patients) (Table 6).

\section{Anticancer treatment}

The treatments and aggressiveness of care in the reaudit period is summarised in Table 4 and Table 5 . $8 \%$ of patients had not received any anticancer therapy whereas $33 \%$ had received one line of treatment, $33 \%$ had received two lines of treatment and 25\% had received three or more lines of treatment. 19 patients of the total 75 deaths $(25 \%)$ had received anticancer treatment within the last 30 days of life. 6 of $47(13 \%)$ patients whose last anticancer treatment was chemotherapy received a dose within the last 30 days of life. This was substantially lower compared with the audit period. This indicator also reduced with respect to endocrine/hormonal treatments (33\%) and remained stable with respect to targeted/ biologics (42\%). There was a substantial increase with regard to immune checkpoint inhibitors. $89 \%$ of patients, whose last treatment was an immune checkpoint inhibitor, received a dose within the last 30 days of life. This is demonstrated in Fig. 1. Of the total number of patients who received chemotherapy, treatment within the last 30 days of life represented $2 \%$ of patients.

\section{Aggressiveness of care}

$92 \%$ of patients were treated with palliative intent. The rate of palliative care or hospice service referral was significantly improved to $80 \%$. Late referrals were less frequent with $39 \%$ of referrals occurring in the last 30 days of life. Treatment within the last 30 days of life was again associated with more patients having more than one hospital admission (17\% vs $8 \%)$. The rate of more than one ED presentation ( $11 \%$ vs $8 \%$ ), ICU admission ( $6 \%$ vs $6 \%$ and hospital admission greater than 14 days was similar (22\% vs $22 \%)$.

\section{Discussion}

Clinical audit is an essential part of clinical governance used to assess current performance and an important tool for practice improvement [29]. Audits have been found to have a small but potential important impact on professional practice [30]. This study reviewed 440 patient deaths and examined for patterns in SACT and other parameters of aggressiveness of care. A multifaceted quality improvement implementation plan was implemented and a re-audit of a further 75 patient deaths was conducted to assess the effect of this intervention. Components of the intervention have previously been proposed by other authors [10, 19]. The intervention was simple and can easily be replicated at other centres. The mechanism of the intervention is multifaceted. The initial education session raises awareness of this issue and reports on current performance. Regular reviews of all cases at morbidity and mortality meetings maintains awareness and allows repeated feedback to clinicians. Mandated repeat assessment of performance status and

Table 5 Treatment and aggressiveness of care in the re-audit period

\begin{tabular}{|c|c|c|c|c|c|c|}
\hline & \multicolumn{2}{|c|}{ All Patients } & \multicolumn{2}{|c|}{ Treatment within last 30 days } & \multicolumn{2}{|c|}{ No treatment within last 30 days } \\
\hline & Number & Percent & Number & Percent & Number & Percent \\
\hline \multicolumn{7}{|l|}{ Last treatment type } \\
\hline Chemotheratpy & 47 & & 6 & $13 \%$ & 41 & $87 \%$ \\
\hline Targeted/biologic & 12 & & 5 & $42 \%$ & 7 & $58 \%$ \\
\hline Endocrine/hormonal & 6 & & 2 & $33 \%$ & 4 & $67 \%$ \\
\hline Immunotherapy & 9 & & 8 & $89 \%$ & 1 & $11 \%$ \\
\hline \multicolumn{7}{|l|}{ Treatment intent } \\
\hline Curative & 6 & $8 \%$ & 1 & $5 \%$ & 5 & $9 \%$ \\
\hline Palliative & 69 & $92 \%$ & 18 & $95 \%$ & 51 & $91 \%$ \\
\hline \multicolumn{7}{|l|}{ Parameters for aggressiveness of care } \\
\hline Palliative care referral & 55 & $80 \%$ & 15 & $83 \%$ & 40 & $78 \%$ \\
\hline Palliative care referral beyond last 30 days & 42 & $61 \%$ & 12 & $67 \%$ & 30 & $59 \%$ \\
\hline More than one emergency presentations & 6 & $9 \%$ & 2 & $11 \%$ & 4 & $8 \%$ \\
\hline More than one hospitalisation & 7 & $10 \%$ & 3 & $17 \%$ & 4 & $8 \%$ \\
\hline Hospitalisation 14 or more days & 15 & $22 \%$ & 4 & $22 \%$ & 11 & $22 \%$ \\
\hline ICU admission & 4 & $6 \%$ & 1 & $6 \%$ & 3 & $6 \%$ \\
\hline
\end{tabular}




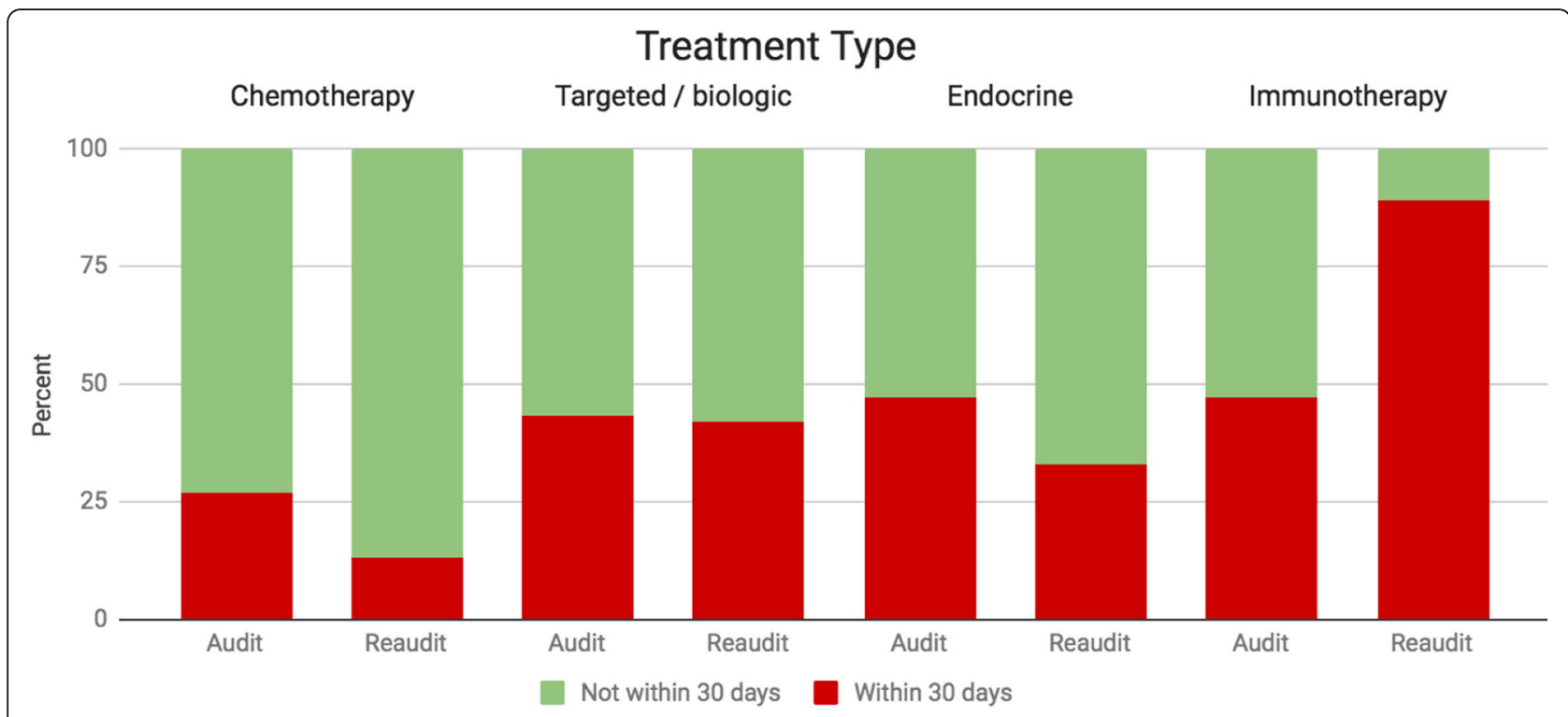

Fig. 1 Comparison of rates of treatment between audit and re-audit period by treatment type

discussion of borderline cases at treatment commencement provide a decision point which can break up treatment inertia. Finally, simplifying referral processes to palliative care and hospice services supports patients, families and clinicians in symptom management, maximising the use of SACT and transitioning to the end of life period.

Overall, the patient population was as expected of a regional cancer centre with a predominance of solid tumour types representing the common cancer diagnoses and a broad spread of patient performance status. The rate of SACT within the last 30 days of life was $27 \%$ in the initial audit period and remained stable at $25 \%$ during the re-audit period. Review of the literature, as summarised in Table 1, did not find a published report to consider all treatment modalities, namely cytotoxic chemotherapy, endocrine and hormonal agents, targeted and biologic agents and immunotherapy. When comparing this figure to other published reports, it is important to note that this statistic is the number of deaths within the last 30 days of life as a proportion of all deaths of patients managed at the Goulburn Valley Health oncology department. A similar statistic in the Australian context was reported by Wein et al. at a rate of $26 \%$ but only included patients treated with palliative intent and did not include immunotherapy [21]. Other authors have reported treatment rates as a proportion of patient deaths between 4 and $38 \%[14,16,18,21-23,28]$.

The more commonly reported statistic is the number of deaths within 30 days of SACT as a proportion of all patients who received SACT. We calculated a comparable statistic where the number of deaths of patients who received chemotherapy within the last 30 days of life expressed as a percentage of all patients who received chemotherapy was initially $8 \%$ and fell substantially to $2 \%$ during the re-audit period. This compares well with reports from other centres and is in fact the lowest reported rate in Australasian region [11, 13, 19, 24-27].

This study is one of only a few to include immunotherapy in assessing mortality within 30 days of treatment. A recent study from New Zealand reported a rate of SACT within the last 30 days of life of $5.2 \%$ [11]. This included chemotherapy, targeted therapies and immunotherapy, but excluded endocrine / hormonal treatments. It should be noted that this was measured as a proportion of all patients who received SACT. Gilsch et al. conducted a retrospective review of 157 deceased patients treated with immune checkpoint inhibitors and reported that $27 \%$ received a dose within the last 30 days of life [4]. This is substantially lower than our rates of $47 \%$ in the audit period and $89 \%$ in the re-audit period.

SACT within the last 30 days of life with cytotoxic chemotherapy occurred in $27 \%$ and in higher proportions in non-chemotherapy treatments, specifically endocrine and hormonal agents $47 \%$, targeted and biologic agents $43 \%$, and immune checkpoint inhibitors $47 \%$. Interestingly, this rate rose to $89 \%$ during the re-audit period with regard to immune checkpoint inhibitors whereas rates for endocrine / hormonal agents and targeted/biologic agents remained stable and the rate of chemotherapy use near the end of life fell to 13\% (Fig. 1). This should be interpreted with caution due to the small patient numbers and short re-audit period. Possible explanations for these trends include the increasing availability and number of indications for immune checkpoint inhibitors over the recent period. 
Table 6 Top 10 most common tumour types in audit and re-audit periods

\begin{tabular}{|c|c|c|c|c|c|}
\hline \multicolumn{3}{|l|}{ Audit } & \multicolumn{3}{|l|}{ Re-audit } \\
\hline Tumour type & Number & Percent & Tumour type & Number & Percent \\
\hline Lung & 87 & 20 & Colorectal & 14 & 19 \\
\hline Colorectal & 62 & 14 & Lung & 10 & 13 \\
\hline Breast & 42 & 10 & Prostate & 7 & 9 \\
\hline Prostate & 40 & 9 & Breast & 6 & 8 \\
\hline Pancreas & 34 & 8 & Upper Gl & 5 & 7 \\
\hline Upper Gl & 29 & 7 & Melanoma & 5 & 7 \\
\hline Urothelial & 18 & 4 & Lymphoma & 4 & 5 \\
\hline Gynaecological & 15 & 3 & Cholangiocarcinoma & 4 & 5 \\
\hline Lymphoma & 14 & 3 & Head and neck & 4 & 5 \\
\hline Melanoma & 10 & 2 & Gynaecological & 3 & 4 \\
\hline
\end{tabular}

Furthermore, non-chemotherapy treatments have a more tolerable side effect profile and may be more accepted by patients and clinicians when treatment decisions are being made. These factors may contribute to a shift in treatment modalities from chemotherapy towards immune checkpoint inhibitors. Also, the composition of tumour types between the audit and re-audit periods was different (Table 6) and may affect the types of treatments used.

When the other parameters of aggressiveness of care are examined, the re-audit period was notable for an increase in palliative care referrals $(78 \%$ vs $65 \%)$ and decrease in late palliative care referrals ( $41 \%$ vs $58 \%)$. This did not seem to affect the other indicators of aggressiveness of care. Similar rates of more than one ED presentation, more than one hospitalisation and ICU admission were seen in the audit and re-audit period. The rate of hospital admission for more than 14 days rose from 14 to $22 \%$ after the intervention. This is demonstrated in Fig. 2. The association of treatment within the last 30 days of life and increased rates of more than one hospitalised was observed before and after the intervention but was not maintained with regard to more than one ED presentation or ICU admission.

Limitations to this project should be noted. Data has been collected in a retrospective manner. Data was collected from patient medical records which relies on complete and accurate documentation. Furthermore, patients in regional areas often have shared care between different centres and therefore a number of outcome events may not be captured in this data collection. The re-audit period was relatively shorter than the initial audit period and the observed trends in practice may attenuate over a longer period of time. The re-audit period

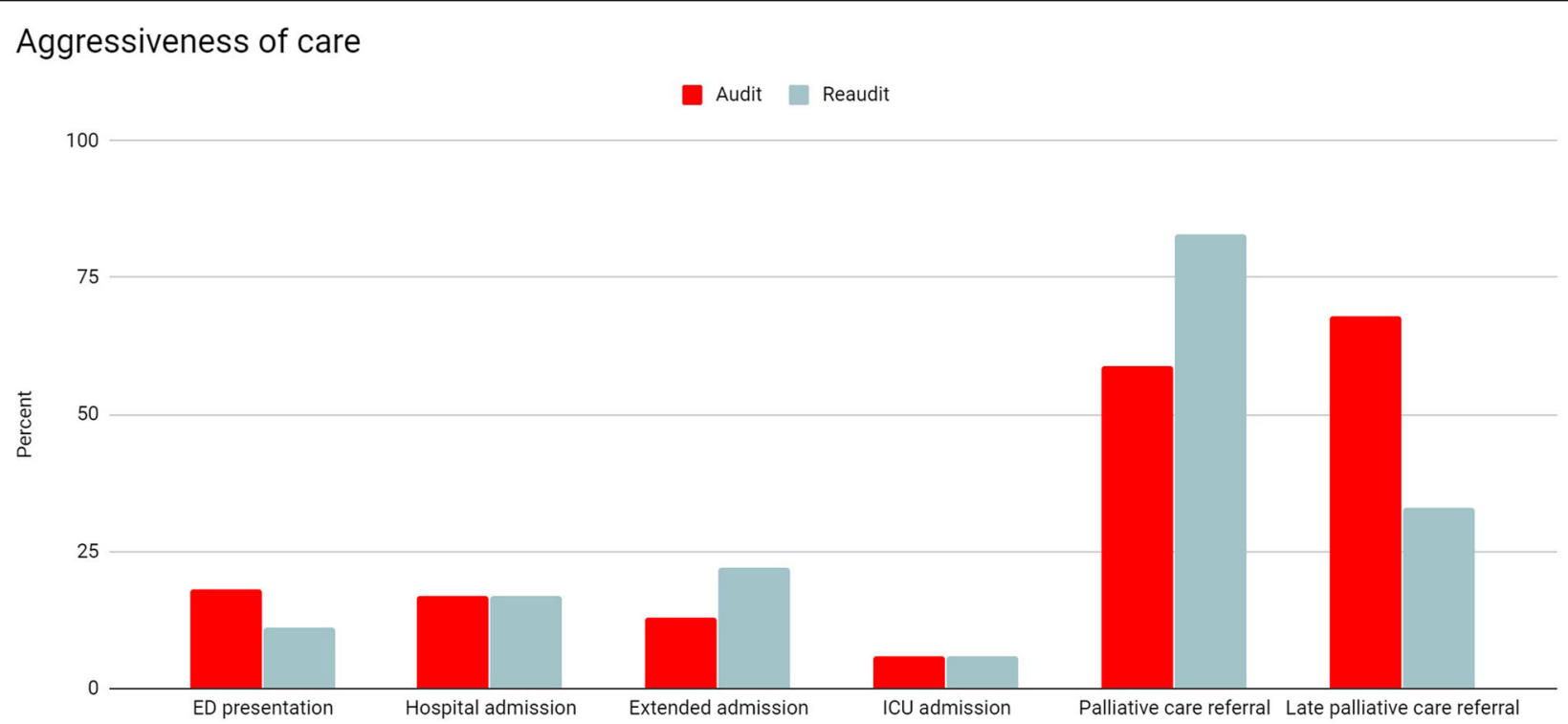

Fig. 2 Comparison of indicators of aggressiveness of care between the audit and re-audit periods 
was considered to have started immediately after the audit period which resulted in a short period of time before clinicians were fully exposed to the improvement implementation plan. The educational meeting and palliative care contacts were enacted within a week of the conclusion of the audit period. However, there may have been a learning curve period as clinicians gained repeated exposure and feedback from the regular case and mortality meetings. Nonetheless, these factors would likely have contributed to an underestimation of the effect of the improvement implementation plan.

\section{Conclusion}

This study provides a contemporaneous benchmark for SACT and other parameters of aggressiveness of care within the last 30 days of life in an Australian regional setting. Importantly, the changing treatment paradigm with the increasing use of immune checkpoint inhibitors and other targeted agents is considered. It also establishes the components of a quality improvement implementation plan and demonstrates its impact on use of SACT and palliative care referral practices. Further research is required into the factors which affect the treatment decision making process in order to ensure quality of care.

\section{Abbreviations}

ASCO: American Society of Clinical Oncology; ECOG: Eastern Cooperative Oncology Group; ED: emergency department; ESMO: European Society of Medical Oncology; ICU: Intensive care unit; NCEPOD: National Confidential Enquiry into Patient Outcome and Death; NSCLC: Non small cell lung cancer; QOL: Quality of life; SACT: Systemic anticancer therapy

\section{Acknowledgements}

Not applicable.

\section{Previous publication}

This study has previously been presented at ASCO Annual Meeting 2019 as a poster.

Abstract: https://meetinglibrary.asco.org/record/177356/abstract

\section{Authors' contributions}

MN contributed to study concept, data acquisition, data analysis and manuscript writing. SK contributed to data acquisition and data analysis. ES contributed to data acquisition and data analysis. AW contributed to study concept and data analysis. BT contributed to study concept and data analysis. AS contributed to study concept and data analysis. JT contributed to study concept and data analysis. All authors read and approved the final manuscript.

\section{Funding}

Not applicable.

\section{Availability of data and materials}

Data used from this study is available from the corresponding author on reasonable request.

\section{Ethics approval and consent to participate}

Appropriate ethics approval was obtained from the Goulburn Valley Health Human Research Ethics Committee. Reference number GVH 28/17.

\section{Consent for publication}

Not applicable.

\section{Competing interests}

The authors declare that they have no competing interests.

\section{Author details}

${ }^{1}$ Austin Health, Melbourne, Australia. ${ }^{2}$ Goulburn Valley Health, Shepparton, Australia. ${ }^{3}$ Peninsula Health, Melbourne, Australia.

Received: 23 September 2019 Accepted: 15 January 2020

Published online: 27 January 2020

\section{References}

1. Earle CC, Park ER, Lai B, Weeks JC, Ayanian JZ, Block S. Identifying potential indicators of the quality of end-of-life cancer care from administrative data. JCO. 2003;21(6):1133-8.

2. Earle $C$, Landrum $M$, Souza J, et al. Aggressiveness of cancer care near the end of life: is it a quality-of-care issue? JCO. 2008;26:3860-6.

3. Wright $A$, Zhang $B$, Keating $N$, et al. Associations between palliative chemotherapy and adult cancer patients' end of life care and place of death: prospective cohort study. BMJ. 2014;348:g1219.

4. Gilsch C, Hagiwara Y, Gilbertson-White S, Gao Y, Lyckholm L. Immune checkpoint inhibitor use near the end of life is associated with poor performance status, lower hospice enrolment, and dying in the hospital. Am J Hosp Pallat Care. 2019:1049909119862785.

5. Prigerson $\mathrm{HG}$, Bao Y, Shah MA, et al. Chemotherapy use, performance status, and quality of life at the end of life. JAMA Oncol. 2015;1(6):778-84.

6. Temel JS, Greer JA, Muzikansky A, et al. Early palliative care for patients with metastatic non-small-cell lung cancer. N Engl J Med. 2010;363:733-42.

7. Greer J, Pirl W, Jackson V, et al. Effect of early palliative care on chemotherapy use and end-of-life care in patients with metastatic nonsmall-cell lung cancer. J Clin Oncol. 2012;30:394-400.

8. Betty R et al. Integration of Palliative Care Into Standard Oncology Care: American Society of Clinical Oncology Clinical Practice Guideline Update. J Clin Oncol 35:96-112. 2016 by American Society of Clinical Oncology.

9. Jordan K, Aapro M, Kaasa S, Ripamonti Cl, Scotté F, Strasser F, Young A, Bruera E, Herrstedt J, Keefe D, Laird B, Walsh D, Douillard JY, Cervantes A. European Society for Medical Oncology (ESMO) position paper on supportive and palliative care. Annals of Oncology. 2018;29(1):36-43.

10. Mort D, Smith N, Protopapa K, et al. A review of the care of patients who died within 30 days of receiving systemic anti-cancer therapy. Department of Health United Kingdom: National confidential enquiry into patient outcome and death; 2008.

11. Ang E, Newton LV. Thirty-day mortality after systemic anticancer treatment as a real-world, quality-of-care indicator: the northland experience. Intern Med J. 2018 Apr;48(4):403-8. https://doi.org/10.1111/imj.13618.

12. Burgers J, Damhuis R. 30-day mortality after the start of systemic anticancer therapy for lung cancer: is it really a useful performance indicator? ERJ Open Res. 2018;4(4). https://doi.org/10.1183/23120541.00030-2018.

13. Gilbar PJ, McPherson I, Aisthrope GG, Kondalsamy-Chennakes S. Systemic anticancer therapy in the last 30 days of life: retrospective audit from an Australian regional Cancer Centre. J Oncol Pharm Pract. 2019 Apr;25(3):599_ 606. https://doi.org/10.1177/1078155217752077.

14. Hiramoto S, Tamaki T, Nagashima K, et al. Prognostic factors in patients who received end-of-life chemotherapy for advanced cancer. Int J Clin Oncol. 2019;24(4):454-9. https://doi.org/10.1007/s10147-018-1363-7.

15. Massa I, Nanni O, Foca F, et al. Chemotherapy and palliative care near endof-life: examining the appropriateness at a cancer institute for colorectal cancer patients. BMC Palliative Care. 2018;17:86.

16. Dasch B, Kalies H, Feddersen B, et al. Care of cancer patients at the end of life in a German university hospital: a retrospective observational study from 2014. PLoS One. 2017 Apr 6;12(4):e0175124. https://doi.org/10.1371/journal.pone.0175124.

17. Falchook A, Dusetzina S, Tian F, et al. Aggressive end-of-life care for metastatic cancer patients younger than age 65 years. J Natl Cancer Inst 2017;109(9). doi: https://doi.org/10.1093/jnci/djx028.

18. Kraut J, Gippetti J, Peterson D, et al. Chemotherapy use near end of life (EOL): measuring real world benchmarks. JCO. 2017;35(Suppl 8):228.

19. Wilson M, Mak W, Firth M, et al. Mortality within 30 days of systemic anticancer therapy at a tertiary cancer Centre: assessing the safety and quality of clinical care. N Z Med J. 2017;130(1460):63-72.

20. Wallington M, Saxon E, Bomb M, et al. 30-day mortality after systemic anticancer treatment for breast and lung cancer in England: a populationbased, observational study. Lancet Oncol. 2016;17:1203-16. 
21. Wein L, Rowe C, Brady B, Handolias D, Lipton L, Pook D, Stanley R, Haines I. Prevalence of systemic anticancer therapy for patients within the last 30 days of life: experience in a private hospital oncology group. Intern Med J. 2017;47(3):280-3.

22. Khoja L, McGurk A, O'Hara C, et al. Mortality within 30 days following systemic anti-cancer therapy, a review of all cases over 4 year period in a tertiary cancer Centre. Eur J Cancer. 2015;51:233-40.

23. Pacetti P, Paganini G, Orlandi M, et al. Chemotherapy in the last 30 days of life of advanced cancer patients. Support Care Cancer. 2015;23:3277-80.

24. Philip J, Hudson P, Bostanci A, et al. Metastatic non-small cell lung cancer: a benchmark for quality end-of-life cancer care? Med J Aust. 2015;202(3):139-43.

25. Andelkovic $\mathrm{V}$. Palliative chemotherapy during the last month of life. JCO. 2013;31(15_suppl):e20662.

26. Zdenkowski N, Cavenagh J, Ku Y, et al. Administration of chemotherapy with palliative intent in the last 30 days of life: the balance between palliation and chemotherapy. Intern Med J. 2013 Nov;43(11):1191-8. https:// doi.org/10.1111/imj.12245.

27. Yoong J, Seah J, Hamilton K, et al. Mortality within 30 days of receiving systemic anti-cancer therapy at a regional oncology unit: what have we learned? Asia-Pacific Journal of Clinical Oncology. 2012;8:325-9.

28. Kao S, Shafiq J, Vardy J, Adams D. Use of chemotherapy at end of life in oncology patients. Ann Oncol. 2009;20:1555-9.

29. Benjamin A. Audit: how to do it in practice. BMJ. 2008;336:1241-5.

30. Ivers N, Jamtvedt G, Flottorp S, Young JM, Odgaard-Jensen J, French SD, O'Brien MA, Johansen M, Grimshaw J, Oxman AD. Audit and feedback: effects on professional practice and healthcare outcomes. Cochrane Database of Systematic Reviews 2012, Issue 6. Art.

\section{Publisher's Note}

Springer Nature remains neutral with regard to jurisdictional claims in published maps and institutional affiliations.

Ready to submit your research? Choose BMC and benefit from:

- fast, convenient online submission

- thorough peer review by experienced researchers in your field

- rapid publication on acceptance

- support for research data, including large and complex data types

- gold Open Access which fosters wider collaboration and increased citations

- maximum visibility for your research: over $100 \mathrm{M}$ website views per year

At $\mathrm{BMC}$, research is always in progress.

Learn more biomedcentral.com/submissions 